\title{
X-maps and Hypsometric Analysis for River Basin Management and Prioritization: The Case of Bohol River Basins, Central Philippines
}

Imelida Genson Torrefranca ( $\square$ imetorrefranca@gmail.com )

Bohol Island State University https://orcid.org/0000-0003-4192-339X

Roland Emerito S Otadoy

University of San Carlos - Talamban Campus

Alejandro F Tongco

University of San Carlos - Talamban Campus

\section{Research}

Keywords: $\chi$-map, divide stability and migration, hypsometric analysis, basin geologic development, river basin management

Posted Date: February 12th, 2021

DOl: https://doi.org/10.21203/rs.3.rs-196247/v1

License: (a) (1) This work is licensed under a Creative Commons Attribution 4.0 International License. Read Full License

Version of Record: A version of this preprint was published at International Journal of River Basin Management on July 3rd, 2022. See the published version at https://doi.org/10.1080/15715124.2022.2092487. 
4 Imelida G. Torrefranca ${ }^{1,2 *}$, Roland Emerito S. Otadoy ${ }^{3,4}$, and Alejandro F. Tongco ${ }^{1}$

$5 \quad{ }^{1}$ School of Engineering, University of San Carlos - TC, Talamban, Cebu City 6000

\section{$\chi$-maps and hypsometric analysis for river basin management}

$$
\text { and prioritization: the case of Bohol River Basins, Central }
$$

\section{Philippines}

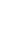

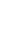

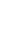

(1)

${ }^{3}$ Department of Physics, University of San Carlos - TC, Talamban, Cebu City 6000

${ }^{2}$ Department of Agricultural and Biosystems Engineering, Bohol Island State Philippines

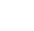

${ }^{4}$ Center for Geoinformatics and Environmental Solutions, University of San Carlos TC, Talamban, Cebu City 6000 Philippines

\section{Philippines}

$$
\text { University - Bilar Campus, Bohol } 6317 \text { Philippines }
$$


$(\chi)$ metric, a proxy for the steady-state river channel elevation, gages the stability of drainage divides while hypsometric analysis quantifies the stages of basin geological development. Using a 30m SRTM DEM and the TopoToolbox tool in MATLAB, $\chi$ values along stream networks are computed. At the channel heads of opposing stream networks of a divide section, equal $\chi$ - values indicate a stable divide while across difference in $\chi$ - values suggest unstable divide with a potential to migrate from low $\chi$ - values towards the high $\chi$ - values side of the divide. To classify the degree of potential divide mobility, the quantity called mean chi difference $\left(\chi_{m d}\right)$ is proposed. The features of the aggressive and victim river streams are visually differentiated using their elevation profiles, map-view arrangement and pathways to discharge points. Hypsometric analysis examines the erosional stages of basins indicated by the hypsometric integrals (HI) and hypsometric curves. A basin and its subbasins show different levels of geologic development that the disaggregation of large basin into small hydrologic units enables the identification of areas of different erosional stages. The prioritization of subbasins considers the intersection of highly mobile divides and highly erosional areas. Over the study area, nine subbasins are identified which are all located at the headwaters of major basins in the island. A considerable earthquaketriggered landslide has been found in one of the identified subbasins. The study presents a new approach in the initial characterization of landforms in order to facilitate the identification and prioritization of highly erodible areas for high consideration especially at the local or village level.

Keywords: $\chi$-map, divide stability and migration, hypsometric analysis, basin geologic development, river basin management

\section{Introduction}


Landforms are functional regions on the earth's surface, and are bounded segments and may be discontinuous [1] that change shape overtime. Landform evolution and its unique characteristics is a time-integrated product of extremely long periods of weathering and surface processes [2], driven primarily by tectonics and climate $[3,4]$. These processes, operating at varying intensities in distinct climate and tectonic systems, formed highly regionalized associations between landforms, ground conditions, geohazards and resources characterizing a geomorphological environment [2]. The current topography is a fingerprint of these processes and is fundamentally the basis of landform dynamics analysis constituting modern geomorphic analysis.

Advances in the quantitative characterization of terrain and processes, and enhancement of theories, observations and modelling of surface and sub-surface processes, are critical to providing knowledge on what governs 'catchment form and function' [5], runoff processes and erosion [6], substantiate ground engineering practices [7], facilitate geo-hazard assessment [8,9], predict spatial patterns of soil properties $[10,11]$ among others. Nonetheless, such information and knowledge are indispensable to developing a sustainable river basin management plan. As Schwanghart et al [12] emphasized, characterizing a river basin is critical for future economic development pathways.

Efforts to characterize the evolution of landscapes give rise to the development of topographic indices which can be used as rapid assessment tools proxy of different surficial processes $[12,13,14,15]$. The fundamental basis is the existing surface topography that resembles the complex interaction of these processes occurring over a geologic time setting. The same topography becomes the fundamental basis for developing river basin management strategies. 
River basins are hydrologic unit comprising of drainage divides and stream channel networks. Drainage divides set the boundary between adjacent basins and any changes in the boundary conditions affect the whole catchment. The stream channels on the other hand, are the pathways that transport water, sediments and nutrients from uplands to oceans. The rate of fluvial erosion along river bedrocks is governed by the stream power model. These elements of a basin are previously assumed to be static however observations of stream capture [16, 17, 18], long-term erosion studies [19] and numerical modelling [20] demonstrated that basin shape and network topology adjust in response to any perturbations to boundary conditions. Erosional topography likewise uses natural drainage basins on the assumption that the form of each drainage basin results from the interaction of slope-wasting and channel-deepening processes within the limits of the drainage divide, and hence that each basin should be treated as a unit [14].

The development of the $\chi$ - metric as a measure of divide stability by Willet et al [21] is fundamentally based on the 'differential rates of river channel erosion on opposite sides of a divide'. It was argued that when disequilibrium exists between opposing river channels, the shared drainage divide is set in motion until equilibrium is reach. $\chi$ is an integral solution to the stream power model proposed by [22] and is expressed as:

$$
\chi=\int_{x_{b}}^{x}\left(\frac{A_{o}}{A(x)}\right)^{\frac{m}{n}} d x
$$

where $A$ is the upstream drainage area, $A_{o}$ is an arbitrary scaling area, $x$ is the location of a point along the channel, $x_{b}$ is the base level, and $m$ and $n$ are empirical constants. A $\chi$ difference across a divide implies disequilibrium. This state of disequilibrium sets the divide in motion moving from lower to higher $\chi$ area until equilibrium is reached. $\chi$ is use to map the horizontal motion of drainage divides and the dynamic evolution of 
river channels, and to identify transient erosional signals [21]. Willett et al [21] found out that $\chi$ - maps are more interesting as they are simple to calculate and also provide a rapid visual assessment of divide stability over a large area, and further lauded the capability of $\chi$ to characterize the variability of river network's topology and geometry in a river basin as they transmit tectonic and/or climatic signals throughout the landscape.

Recent studies on the use of $\chi$ - metric has established its strong relation to predicting landslide events which is useful in assessing hazard vulnerability of physical infrastructure. An investigation was carried out by Dahlquist et al [23] on the role of landslide-generating events on the reorganizations of drainage basins and landscape evolution. Their study conducted a topographic analysis using channel metrics to assess drainage divide stability and migration over areas where natural disasters have triggered large landslides. The study found out that the resulting area exchange between basins due to landslides was consistent with landforms that advanced towards steady-state conditions as suggested by the channel metrics. Similarly, Schwanghart et al [12] used the topographic metric that expresses river steepness together with the earthquake ground acceleration to predict the degree of earthquake damage to hydropower projects in the Himalayan region. Using these metrics, the study identified some areas along the Himalayan river network as unsuitable for hydropower infrastructure due to high probabilities of earthquake-triggered landslides.

Hypsometry quantifies the erosion proneness and stage of geologic development of a basin [14]. Hypsometric analysis examines the distribution of ground surface area, or horizontal cross-sectional area, of a landmass with respect to elevation [15]. The hypsometric curve and hypsometric integral (HI) of drainage basins are common tectonic geomorphologic indices [24]. The geometry of the hypsometric curve classifies 
a basin into different stages of geologic development while HI represents the area under this curve and expresses the volume of a basin that has not been eroded but is not directly related to relative active tectonics [25]. In the analysis of El Hamdouni et al [25], the shapes of the hypsometric curves were considered whether convex in its upper portion, convex to concave or convex in the lower portion, and also the corresponding HI value. They also classified HI values into high (>0.5), intermediate (between 0.4 to 0.5$)$ and low $(<0.4)$. High HI values were convex shape, intermediate HI values were convex to concave or straight, and low HI values tended to have concave shapes [25]. Together with hypsometric curve, high HI values were possibly associated with young active tectonics while low HI values were related to older landscapes that have been more eroded and less impacted by recent active tectonics, according to the study. An assumption was made that if the shape of the curve in its lower portion was convex, it may relate to uplift along a fault or perhaps uplift associated with recent folding [25].

Hypsometric analyses have been incorporated in a number of geomorphologic studies. Together with other topographic metrics, hypsometric analysis was used to assess key drivers of landscape changes associated with climate change and tectonic activity in ground engineering practice in the study of Geach et al [7]. Their study identified engineering constraints and geohazards, and created a constraint map that was used to target areas for further investigation and also to advise construction methodologies and limitations. Radaigeh and Mosar [26] investigated on the tectonic controls of fluvial landscapes and drainage development in western Switzerland using classical geomorphic indices including hypsometry. Their study used a high-precision DEM for the hypsometric analysis which revealed that abnormally high HI were spatially associated with hanging walls of thrust fault while low ones were observed along paleo-ice stream pathways. Together with other geomorphic indices, the study 
confirmed significant tectonic controls on the evolution of drainage systems and uncovered evidences of reactivated faults.

In the southern Coastal Range of eastern Taiwan, the effects of tectonic uplift and basin scale on HI were examined by Chen at al [24]. The study proposed a 'scaledependence index' (SDI) - the logarithmic regression coefficient between the mean area and the mean HI of every order of subbasin, to represent the degree of basin HI scale dependence and to distinguish a basin's topographic tendency between range interior and range front. Low SDI corresponded to high scale dependence. The study found out that basins approaching a range interior steady state have low scale dependence while their HI values positively correlate with rock uplift rates. Further, the study observed that basins approaching a range front non-steady state were highly scale dependent but their HI were not correlated with rock uplift rate.

Singh [14] carried out a hypsometric analysis to estimate the erosion status of basins and to prioritize areas for soil and water conservation measures. Looking at two basins in the lesser Himalayan region, his research enabled the identification of basins highly susceptible to erosion. The study also found out that higher annual sediment yield come from basin with higher hypsometric value indicating youthful nature of landmass.

This study is set out to explore the integration of the $\chi$-metric [27] and the commonly used hypsometric analysis [15] as rapid assessment tools in river basin management. Specifically, the study aims to: a) assess the stability of drainage divides of river basins using the $\chi$-metric and determine the degree of basin disequilibrium by evaluating the mean $\chi$ difference of unstable divides, b) examine the spatial variation erosional landforms using hypsometric analysis, and c) identify and map highly dynamic and erosional subbasins. The methodology developed is applied in the island of Bohol, Philippines. As a rapid assessment tool developed in this study, the 
identification and prioritization of highly erosional areas with their migrating divides is possible thus facilitating resource planning process. The study is limited to demonstration of the use of these tools while further studies are needed to validate the results.

\section{Materials and methods}

\subsection{The study area and the flow of analysis}

Figure 1 shows the geographic location of the study area. The Philippine Archipelago is located about hundred kilometers off the Asian continent between Pacific and South China Sea, and is made up of more than 7,100 islands. It is confined between the Sundaland-Eurasian plate on the west and the Philippine sea plate on the east. A group of islands in the central Philippines is geologically described as 'made up several Cretaceous oceanic lithosphere that were created and emplaced in a variety of geologic setting and manner' [28]. These islands emerges from the sea in about MidTertiary [29].

Figure 1. Geographic location of the study site.

Bohol Island covers about $4821 \mathrm{~km}^{2}$ of land area where around $66 \%$ of the area is into agriculture use. The drainage morphology of the island consists of two major basins dissecting the central part, namely: the Loboc and the Wahig-Inabanga River Basins, the former discharges in the southwestern side while the latter drains to the northern side of the island. Both basins are of high economic importance where the Loboc River Basin hosts the famed Loboc River while the Wahig-Inabanga River Basin supports agriculture activities.

Using the climate data of the PAGASA-Tagbilaran Station (2000-2012), the mean annual rainfall is found to be $1653 \mathrm{~mm}$ where April is the driest month and December as the wettest month with $78 \mathrm{~mm}$ and $185 \mathrm{~mm}$ of rainfall, respectively. The temperature 
ranges from $24{ }^{\circ} \mathrm{C}$ to $32^{\circ} \mathrm{C}$ while the average relative humidity is $83 \%$. On the average, 20 typhoons visit the country annually where around three of these passes the island. As a tectonically active archipelago, earthquake strikes are a commonplace and the most recent and destructive one is the Mw7.2 in October 10, 2013. Kobayashi [30] mapped the ground displacement associated with this earthquake.

The digital elevation dataset used in the succeeding analysis is a Shuttle Radar Topography Mission (SRTM) data downloaded from https://earthexplorer.usgs.gov. The elevation data, officially published in September 2014, is a void filled data with a resolution of 1 arc-second $(\sim 30 \mathrm{~m})$. The study area consists of four tiles. Preprocessing include tile mosaicking, projecting to WGS UTM 1984 Zone 51N, and the extraction of the study area. The flow of analysis is given in Figure 2. The following sub-sections describes the process of arriving at the top priority subbasins using the hypsometric and $\chi$ analyses.

Figure 2. Flow of analysis and the methods.

\subsection{Divide stability analysis using $\chi$}

$\chi$ is computed using the DivideTools [13], a series of Matlab-based tools for analyzing drainage divide stability built on top of TopoToolbox [31]. The analysis starts off with running the DivideStability function which computes the values of the metrics for drainage divide stability. In this study, we are interested only in the $\chi$-metric as a topographic proxy for assessing disequilibrium of drainage boundaries. Inputs to run the DivideStability function are a DEM and a flow direction grid, and the parameter values given in Table 1 . The minimum accumulation area is used to define stream initiation. The theta_ref or the reference concavity is a constant for calculating $\chi$ and the 'min_elevation' parameter is use to set minimum elevation for base level. 
To evaluate across divide stability for a selected divide section, the

AcrossDivide function is used. The function allows the selection of a divide, segmentation of a heterogenous divide into sections, and the calculation of $\chi$ quantities. In this study, the standard deviation is used as the criteria to define whether a divide is stable or not. The results are shown in a histogram which displays the degree of separation or overlap of $\chi$ values on either side of a divide. As described by Forte $\&$ Whipple (2018), the stability of a divide is based on a criteria wherein the 'mean of one side of the divide is within one standard deviation of the mean of the other side', otherwise a divide is unstable. The direction of potential movement is from the side where channels have lower $\chi$-values to the side with higher $\chi$-values. For unstable divides, the $\chi$-values at the channel heads at both sides of the divide are extracted and their means are computed. A measure called the mean chi difference, $\chi_{m d}$, for each divide section is proposed which represents the degree of potential divide mobility, computed as:

$$
\chi_{m d}=\left|\chi_{m e a n, 1}-\chi_{m e a n, 2}\right|
$$

where, $\chi_{\text {mean }}$ is the mean $\chi$-values, while subscripts 1 and 2 refer to the sides of the divide section. The $\chi_{m d}$ values are classified into low $\left(\chi_{m d}<135\right)$, moderate $(135 \geq$ $\left.\chi_{m d} \leq 255\right)$ and high $\left(\chi_{m d}>255\right)$. The quantitative classification is based on the range of $\chi_{m d}-$ values of all identified unstable divide sections in the study area.

The river networks that share an unstable divide are described in Willett et al [21] Willett et al (2014) as constantly adjusting their drainage areas either by divide migration or river capture until an equilibrium condition is achieved. These opposing river networks are called as the aggressive and the victim streams having lower $\chi$ values and higher $\chi$-values, respectively [21]. To show the features of these river networks, a sample unstable divide is selected and the opposing rivers are extracted. 
Their corresponding pathways are mapped, and their $\chi$ values and elevation profiles are plotted. Visual presentation of $\chi$ differences across divides is facilitated by exporting the outputs to a GIS platform for analysis and map rendering.

\subsection{Hypsometric analysis}

Hypsometric analysis is used to evaluate the stages of geologic development and assess the relative tectonic activity of the drainage basins [32]. The analysis produces two indicators: the hypsometric curve and the hypsometric integral. The hypsometric curve describes the spatial distribution of basin area versus the altitude of the basin and its shape indicates the degree of dissection and the stage of development of the basin [32] while the hypsometric integral is the amount of landmass that is left after erosion.

The hypsometric analysis set offs with the delineation of basins and subbasins (Figure 2). This is carried out using the SWAT Watershed Delineator (https://swat.tamu.edu/). The tool requires a DEM as input, creates flow direction and flow accumulation rasters, and suggests a range of basin area or number of pixels for stream initiation. To delineate a high drainage density, the delineator is run under different basin areas, even below the value recommended by the delineator. This is done to accommodate small catchments along the coastlines and to disaggregate large basins into smaller subbasins. However, due to limitations in computing capacity, subbasin delineation settles to a 300-ha minimum upslope area for stream initiation. The tool also parameterizes each hydrologic unit and these parameter values are stored in the attribute tables and in text files.

The hypsometric curve and hypsometric integral (HI) are computed for each basin and subbasin. The basin and subbasin parameters computed previously are exported to a spreadsheet to calculate the relative area $\left(\frac{a}{A}\right)$ and relative altitude $\left(\frac{h}{H}\right)$ 
where $a, A, h$ and $H$ refer to area within the two adjacent contour lines, total area of the basin or subbasin, contour interval, and relief of the basin or subbasin, respectively. The hypsometric curve is a plot of the relative area versus the relative altitude. The value of $\frac{a}{A}$ varies from 1.0 to 0.0 at the lowest point in the basin where $\frac{h}{H}=0$ to 0.0 at the highest point of the basin where $\frac{h}{H}=1$. The hypsometric integral $(H I)$ computed as:

$$
H I=\frac{\left(Z_{\text {mean }}-Z_{\min }\right)}{\left(Z_{\max }-Z_{\min }\right)}
$$

where $Z_{\text {mean }}, Z_{\text {min }}$, and $Z_{\text {max }}$ refers to mean, minimum and maximum elevations, respectively. The subbasin polygons are converted to points and the kriging interpolation method is used to create a continuous surface of HI. To demonstrate the variation of hypsometric attributes, a major basin and three random subbasins within it are selected. The spatial variation of $\mathrm{HI}$ across the basin and its hypsometric curve is compared with the hypsometric attributes of the smaller subbasins.

Hypsometric curves are classified by many geomorphologists according to their shape and the corresponding HI values (e.g.. [25] and [33]). Pavano et al [33] adopted the foregoing classification: A hypsometric curve characterized by downward concave curve with $\mathrm{HI}$ values greater than 0.6 indicate a youthful condition or inequilibrium stage where the basin experiences an active base level fall. Hypsometric curves having an S-shape without any evidence of concavity and HI values between 0.35 and 0.6 indicate a mature or equilibrium stage. The curves with upward concavity and HI values less than 0.35 indicate a monadnock stage or an old phase. Other studies used different HI values, but in here, the classification adopted by Pavano et al [33] is applied.

\subsection{Basin dynamics at subbasin scale for prioritization}

To understand the dynamics of landform evolution relative to divide stability and stages of erosional development, further analysis is conducted by overlaying the divide stability maps on the hypsometric integral surface. From the divide stability map, 
divide sections with $\chi_{m d}>255$ are highlighted. The subbasins that intersect with these divide sections are selected. These subbasins are inspected and rank according to their $\mathrm{HI}$ values. The list of subbasins is decreased by selecting only those areas with $\mathrm{HI} \geq$ 0.5. The hypsometric curves of these subbasins are inspected. The final list of subbasins is considered as the top priority areas described as highly erodible subbasins with highly mobile divides.

\section{Results and Discussion}

\subsection{Stability of divides between major river basins and at the headwaters}

The island of Bohol is one of the tectonically active islands in the Philippine Archipelago, a major factor that leads to the development and formation of unique landform features. We investigate on the dynamics of river basins, their divides and the network of stream channels using $\chi$-maps. The $\chi$-map of the island is shown in Figure 3. The stream network is mapped using the $\chi$-values, and visual presentation uses color pallet classified by equal interval method. At each divide, disequilibrium is indicated by the contrasting colors of the opposing stream channels while similar stream color indicates stable divide. Figure 3A highlights the major basins in the island and emphasis is directed on the stability of their divides. By visual inspection, it is shown that between these major basins, there are divide sections that are unstable as indicated by the contrasting colors while there are also divide sections that are stable as shown by similar color. However, it is notable that at the headwaters in the southernmost portion of the island, divide sections shared between major basins and smaller basins facing the southern coast are showing highly contrasting colors indicating high $\chi$ anomalies.

Figure 3. $\chi$ - map and the major basins in the study area. A) Highlights the major basins in the island. B) $\chi$ - map of a stable divide and its histogram. C) $\chi$ - map of an unstable divide and its histogram. 
To investigate quantitatively the $\chi$ similarities and differences of individual divide section, Forte and Whipple [13] use the histogram of $\chi$ values at the channel heads of either side of the divide. In this study, two sample histograms of stable and unstable divides are selected and their locations are shown in Figure $2 \mathrm{~B}$ and $2 \mathrm{C}$, respectively. The histogram in Figure 2B shows overlapping of $\chi$-values of the opposing channel heads. It also shows that the mean $\chi$-value of one side of the divide is within one standard deviation of the mean $\chi$-value of the other side. This is the conservative criteria used by Forte and Whipple [13] to determine if a divide is stable or not. The histogram in Figure $2 \mathrm{C}$ shows a wide separation of $\chi$-values at the channel heads of the opposite streams. The figure also shows that the mean $\chi$-value of one side of the divide is far from one standard deviation of the mean $\chi$-value of the other side, indicating that the divide is unstable. In this case, the divide is migrating from the low $\chi$-value side to the high $\chi$-value side of the divide, or towards the north direction.

The dynamics of the drainage divides at the headwater of major basins imply reductions in the catchment areas of the major watersheds while extending the drainage areas of the smaller drainage basins. This also means that differential erosion rates exist across the divide: a higher erosion rate in southern side and a lower erosion rate at the northern side of the divide. On the other hand, stable divides could mean that erosion processes at both sides of the divide are more or less at the same rates.

\subsection{Mean chi difference $\left(\chi_{m d}\right)$ and divide migration}

The $\chi_{m d}$ of a divide is a quantitative measure of the anomaly between opposing channel heads that share a divide. It is proposed to show the extent of $\chi$ differences which can be used as an indicator of the degree of potential divide mobility: the higher the $\chi_{m d}$, the higher the degree of divide migration. Figure 4 highlights the divide sections in the study area, their spatial variation and the direction of migration. The 
mobile divide sections in Figure 4A are classified based on $\chi_{m d}$ described in Section 2.2. Divides with high $\chi_{m d}$ are located at the headwaters of the major basins that border smaller basins draining towards the southern coast of the island. These divides extend in the SW-NE direction and traverse over rocks formed during the Miocene-Pliocene periods. Other classes of $\chi_{m d}$ are dispersed and found to be between the major and smaller basins that face east and northwest coastal areas. Between major basins, divides are stable specially in the interior part of the island. However, in the eastern side of the island, divides between major basins are predicted to be migrating at a low to moderate levels. Though $\chi_{m d}$ criteria presented in this study is arbitrary but is useful in illustrating the purpose of the study.

Figure 4. Divide sections' $\chi_{m d}$ and direction of migration. A) Divide sections colored according to $\chi_{m d}$ classification and laid over the geology of the area. B) A rose diagram showing the direction of potential migration of unstable divides.

For the selected divides predicted to be migrating, the distribution and the direction of potential movement is shown in Figure 4B. There are 14\%, $40 \%$ and $47 \%$ divides classified under high, moderate and low degree of potential mobility, respectively. Of the total identified divides, $28 \%$ are moving in the $\mathrm{N}$ and $\mathrm{NW}$ directions, $5 \%$ towards the west while $67 \%$ are heading towards the S, SE and SW directions. Divides classified as high are moving towards the northwest direction. These are the divides located at the headwaters of major basins that border smaller basins facing to the south. Six out of nine divides heading towards the south are classified as moderate. Of the 10 divides inclined towards the southwest direction, seven divides are classified low. At this point, there is little details on the geology of the island that can associate with the pattern of $\chi_{m d}$ and their migration directions but it is shown that the island consist of different geological formations which may have different erodibilities and could 
potentially have impacts on divide mobility. Climate on the hand may have a hand on this spatial difference of $\chi_{m d}$ as the island is often visited by strong typhoons annually. But since the island is quite small and is surrounded by other islands, it is interesting to look at their significant contribution, if there are, to the $\chi_{m d}$ anomalies found.

Schwanghart [34] introduce the $\chi$ - inferiority concept which determines $\chi$ value on each side of a divide and identify which side is more inferior compared to the other. Victim sides which have higher $\chi$-value are more inferior and that potential migration proceeds from low $\chi$ towards the high $\chi$ areas. However, with the proposed $\chi_{m d}$, the divide section itself is assigned a degree of potential migration. Since basins are bounded by divide sections, the $\chi_{m d}$ of its boundaries This way, we can integrate this information with the stage of geologic development of a basin. This facilitates the identification of high priority areas as targets for conservation goals.

\subsection{Disequilibrium basin and its river network}

The elevation profile of streams found at both sides of a mobile divide may give additional information on the dynamics of a landform. We select an area where $\chi$ shows sharp discontinuity across a divide, extract two river profiles that meet at a divide and investigate on the $\chi$-values and the actual elevation profiles of the rivers, as shown in Figure 5. The divide has a $\chi_{m d}$ of $367 \mathrm{~m}$, and its degree of migration is classified as high. The figure shows the map view of two opposing river channels which share an unstable divide predicted to migrate in a northwest direction, and identifies the victim and the aggressor sides. Figure 5A shows the spatial distribution of $\chi$ where a sharp discontinuity across the landscape is emphasized. It is noted that smaller catchment along the coastal area has low $\chi$-value compared to a major catchment located interior of the island. Both rivers discharge to the southern coast of the island but their pathways and lengths differ remarkedly. The victim side has a channel length of $78.3 \mathrm{~km}$ and is 
meandering towards its discharge point. On the other hand, the aggressor side extends its length to only $17.5 \mathrm{~km}$ long and goes straight to its outlet point. Figure 5B suggest that the meandering victim river could have passed through plains and rocks walls which gave way to soft soil allowing it to shift its banks and change courses towards the sea. On the other hand, the aggressive stream could have crossed through mountains and carved steep-walled valley where its course is set on rocks. A dearth of lithological properties in the island limits information about the nature of these two different rivers. Figure 5. $\chi$-map of disequilibrium basins and the profiles of the two opposing river networks that meet at the divide. A) Map view of the pathways of two opposing rivers (Inset: histogram showing wide difference of the chi values). B) Longitudinal profile of the opposing streams. C) $\chi$-transformed profile of the two opposing rivers.

Both channels have the same elevation drop but their steady state river channel elevation profile have a mean difference of $367 \mathrm{~m}$ (Figure 5C). This wide $\chi$ difference is also depicted in the inset histogram showing a wide disparity of the $\chi$-values at the channel heads. This seemingly large difference in $\chi$-values suggests a state of disequilibrium between the two rivers and also indicates higher erosion rates on the southeast side (aggressor side) of the divide compared to northwest side (victim side). This has prompt divide migration towards the northwest side or from the lower $\chi$ - value to higher $\chi$ - value channels. One of the repercussions is in terms of changes in drainage areas: the aggressive side is gaining drainage area while the victim side losses some of its drainage area. In seismically active landscape, a study by Wolfgang Schwanghart et al. (2018) found out that rivers having high steepness index, $M_{\chi}$ (defined as the $d z / d \chi)$, have high probability of landslide-triggered earthquake that are detrimental to physical infrastructures such as hydropower plants.

\subsection{Hypsometric analysis at different scales}


Hypsometric analysis provide information on the erosion status of basins which is used as the basis for prioritizing areas for conservation measures [14]. Figure 6 shows the results of the hypsometric analysis in the island and across a major basin, and the hypsometric curves of a major basin and selected subbasins within it. The spatial pattern of landform changes in the island is notable in Figure 6A. HI values in the island range from 0.1 to 0.6 where high values are mostly found in the headwater areas of major basins that border south-facing smaller catchments. Patches of high HI values are also located in the western part of the island and in the lower portion of the Wahig-Inabanga River Basin (Figure 6B). As one of the major basins in the island, focus is on the WahigInabanga River Basin because of its high economic importance as the primary agriculture area. Within the Wahig-Inabanga River Basin, three randomly selected subbasins with different $\mathrm{HI}$ values are compared in terms of their $\mathrm{HI}$ values and hypsometric curves. Since these curves use nondimensional parameters, they can be described and compared irrespective of true scale (Strahler, 1952).

Figure 6 Spatial variation of the hypsometric integral in A) island and in the B) major basin. C) hypsometric curves of the basin and selected subbasins. Reference hypsometric curves adopted from Pavano et al. (2019).

The Wahig-Inabanga River Basin drains towards the north of the island and has an $\mathrm{HI}$ value of 0.22 . Subbasin 431 , draining towards the main river from the south towards the north, is located at the headwater of the basin indicates an HI value of 0.69. In the middle of the basin, subbasin 260 drains from the west to the east and gives an HI of 0.28. Subbasin 103 drains from the north to the south in the lower part of the basin and demonstrates an HI of 0.58. The Wahig-Inabanga River Basin is generally in its old stages and is graded to base level so that only $22 \%$ of the its total landmass has remained after erosion. Subbasin 260 has undergo erosion that only $28 \%$ of its original landmass 
is left. Subbasins 431 and 103 are highly erosional areas where 69\% and 58\% of their total land mass, respectively, have remained which may be subject to further erosion.

Meanwhile the hypsometric curves, as shown in Figure 6C, of the basin and of the subbasins vary in terms of shape and pattern which translate into stages of basin development: young (convex up), mature (S-shape) and old (concave up). The area below each hypsometric curve indicates the amount of remaining land masses left after erosion [15]: the higher the HI values, the higher is the remaining volume of material and an indicator of still highly erosional landscape. The hypsometric curve of the Wahig-Inabanga River Basin concaves upward while it crosses below the center of the diagram. The three other subbasins have hypsometric curves showing different patterns. Subbasin 431, located in the upstream portion of the basin, resemble a younger formation. Its curve is convex up and passes above the center of the diagram. Subbasin 260 , located in the middle of the basin, has its hypsometric curve concave up but is less concave than the bigger basin, indicating an old subbasin. Lastly, subbasin 103 in the lower part of the basin has an S-shape curve. This curve indicates a subbasin that is in transition to a mature stage. Although the whole Wahig-Inabanga River Basin is described as an old drainage unit but investigating on its smaller subbasins, we found areas of transient erosional landscapes where erosion rates can vary from low to high as indicated by their stages of development. The convexity of the hypsometric curve is an indicator of the erosional stage of a basin (Strahler, 1952; Ohmori, 1993). The younger less eroded basins yield convex shapes with higher hypsometric integrals. The disaggregation of the Wahig-Inabanga River Basin into smaller units enable us to find highly erosional areas that need immediate attention and of high consideration in the planning process for basin development and management.

\subsection{Landform dynamics prioritization}


The $\chi_{m d}$ value classifies a mobile divide into different degrees of mobility

while the hypsometric analyses identify catchment areas that are highly erosional. Since basins and subbasins are associated with divides and their catchment areas, we identify and prioritize them based on these indicators. There are six divide sections with high $\chi_{m d}$ as shown in Figure 4A. These divide sections are shared with 24 subbasins whose HI values range from $0.24-0.69$, as shown in Figure 7, with catchment areas ranging from 382 ha to 1233 ha. By considering only subbasins with HI values of 0.5 and up, the list reduces to nine subbasins. These subbasins have catchment areas where more than $50 \%$ of their total landmass remaining after erosion so are considered high erosionprone areas and their drainage divides are classified with high $\chi_{m d}$. The hypsometric curves of these nine subbasins exhibit different patterns which are associated with different erosion processes that are happening in this individual subbasins. All of them are in disequilibrium stages as described in Strahler [15].

The study area is one of the tectonically active islands in the country. In those subbasins where $\chi$-values are high, there is a possibility of the occurrence of earthquake-triggered landslides which may be damaging to properties and lives. Such event has been recorded in one of these subbasins where the 2005 Mayana landslide had occurred, as shown in Figure 8. The landslide started as a rock fall along a very steep northwest-trending fault scarp which was triggered by a 4.9 magnitude earthquake that occurred about 3 months prior to the event [35]. On these areas, divide instability is predicted by $\chi$ while high erosion susceptibility is anticipated based on the hypsometric analysis. It is noted that seismic disturbance may not manifest instantaneously but may later come out as seismic processes generate and possibly increase instability of rock formation, similar to this landslide event in Mayana. 
Figure 7. Map of the subbasins that share with high $\chi_{m d}$ divide sections. The color indicates HI values (light to dark means low to high HI). The dark-colored subbasins have $\mathrm{HI} \geq 0.5$. In one of these subbasins, the 2005 Mayana landslide had occurred. Inset is the latest satellite image of the landslide area extracted from Google Earth. Below are the hypsometric curves of the nine subbasins arranged from low to high HI values.

\section{Conclusion}

Identification and prioritization of areas for conservation is a challenge for developing countries due to limited resources to fund conservation-related programs and projects. For an area where natural disasters are a commonplace, prioritization has to reconsider the dynamics of landforms shape by tectonic and climatic forces.

The study presents a method which integrates a proxy for steady state channel elevation, $\chi$, and the hypsometric analysis in the characterization phase of developing a sustainable basin management plan. The $\chi$ metric provides information on the stability and potential mobility of a divide based on the steady-state elevation profile of river networks. Anomalies in $\chi$-values at the channel heads of opposing river networks that meet at a common divide indicate unstable drainage boundaries and a potential divide migration from areas of low to high $\chi$-values. This potential future divide migration is associated with changes in drainage area, a basin either losses or gains catchment area.

On the other hand, the hypsometric analyses, indicated by the hypsometric curve and hypsometric integral, shows the erosional potential of a landscape based on the elevation-area relationships. A basin in general can be identified as an old one and is stable but there could be areas within that basin that are at their earlier stage of geological development. Disaggregation of a basin into smaller subbasins enable us to 
identify highly erosional areas which must be targeted for soil and water conservation programs.

In this exercise, the topographic metric, $\chi$, is integrated with hypsometric analysis, and a new metric is introduced, $\chi_{m d}$, to develop criteria that allow for the selection of target areas for conservation. Results of the study emphasize the importance of incorporating the $\chi_{m d}$ into the routine of basin characterization practice and give us valuable insights about the stability of divide sections as an important factor in identifying target areas. The intersection of highly unstable divides and the highly erosional areas help us narrow down further target areas which facilitate prioritization process.

The method presented could be used as a rapid assessment tool in the characterization phase of developing river basin management program. This approach may be used in conjunction with other existing catchment characterization tools to guide planners on allocating landforms for development purposes or for conservation goals especially at the local or village level.

\section{Declarations}

\section{Availability of data and materials}

The datasets generated and analyzed in this study are submitted together with the manuscript. Such datasets are available from the corresponding author on reasonable request.

\section{Competing Interests}

The authors declare that they have no competing interests.

\section{Funding}


This work was supported by a graduate scholarship program of the Department of Science and Technology - Engineering Research and Development Technology (DOST-ERDT) Philippines.

\section{Authors 'contributions}

IGT initiated the idea of integrating chi maps and hypsometry into river basin management, and the proposed mean chi difference indicator. RESO introduced the use of chi maps for drainage mobility while AFT provide GIS-based hypsometric analysis. Both provide technical guidance in preparing the research. IGT carried out the computing process. The authors contributed in the analyses and interpretation of the results. IGT wrote the paper. RESO and AFT contributed to the paper revision. All authors read and approved the final manuscript.

\section{Acknowledgements}

The authors are grateful to the USGS-SRTM for the free DEM data (https://www.usgs.gov/centers/eros), to the developers of TopoToolbox for the free and open source program for the analysis of digital elevation models (https://topotoolbox.wordpress.com/topotoolbox/), to the Soil and Water Assessment Tool (SWAT)-watershed delineator, a free hydrologic model (https://swat.tamu.edu/), and to the graduate scholarship program of Department of Science and Technology Engineering Research and Development Technology (DOST-ERDT), Philippines for the fund support.

\section{References}

[1] I. S. Evans, "Geomorphometry and landform mapping: What is a landform?," Geomorphology, vol. 137, no. 1, pp. 94-106, 2012.

[2] P. Fookes and M. Lee, "1 . Introduction to Engineering Geomorphology," in Geomorphology for Engineers, P. Fookes, M. Lee, and G. Milligan, Eds. 
[3] A. C. Whittaker, "How do landscapes record tectonics and climate?," Lithosphere, vol. 4, no. 2, pp. 160-164, 2012.

[4] S. M. Mudd, M. Attal, D. T. Milodowski, S. W. D. Grieve, and D. A. Valters, "A statistical framework to quantify spatial variation in channel gradients using the integral method of channel profile analysis," J. Geophys. Res. Earth Surf., vol. 119, no. 2, pp. 138-152, 2014.

[5] G. E. Tucker and G. R. Hancock, "Modelling landscape evolution," Earth Surf. Process. Landforms, vol. 35, pp. 28-50, 2010.

[6] L. Zevenbergen and C. Thorne, "Quantitative Analysis of Land Surface Topography," Earth Surf. Process. landforms, vol. 12, pp. 47-56, 1987.

[7] M. R. Geach, M. Stokes, and A. Hart, "The application of geomorphic indices in terrain analysis for ground engineering practice," Eng. Geol., vol. 217, pp. 122$140,2017$.

[8] C. Lai, Z. Wang, B. Yang, X. Bai, S. Zhao, and X. Chen, "Flood hazard risk assessment model based on random forest," J. Hydrol., vol. 527, pp. 1130-1141, 2015.

[9] G. L. Bennett, S. R. Miller, J. J. Roering, and D. A. Schmidt, "Landslides, threshold slopes, and the survival of relict terrain in the wake of the Mendocino Triple Junction,” Geology, vol. 44, no. 5, pp. 363-366, 2016.

[10] H. F. Wilson, S. Satchithanantham, A. P. Moulin, and A. J. Glenn, "Soil phosphorus spatial variability due to landform, tillage, and input management: A case study of small watersheds in southwestern Manitoba," Geoderma, vol. 280, pp. 14-21, 2016.

[11] Z. Mosleh, M. H. Salehi, A. Jafari, I. E. Borujeni, and A. Mehnatkesh, "The 
effectiveness of digital soil mapping to predict soil properties over low-relief areas," Environ. Monit. Assess., vol. 188, no. 3, pp. 1-13, 2016.

[12] W. Schwanghart, M. Ryan, and O. Korup, "Topographic and seismic constraints on the vulnerability of Himalayan hydropower," Am. Geophys. Union, 2018.

[13] A. M. Forte and K. X. Whipple, "Criteria and tools for determining drainage divide stability," Earth Planet. Sci. Lett., vol. 493, pp. 102-117, 2018.

[14] O. Singh, "Hypsometry and erosion proneness: a case study in the lesser Himalayan Watersheds," J. Soil Water Conserv., no. 2, pp. 53-59, 2009.

[15] A. Strahler, "Hypsometric (Area-Altitude) Analysis of Erosional Topography," Bull. Geol. Soc. Am., vol. 63, no. 2, pp. 1117-1142, 1952.

[16] R. Linkevičiene, "Impact of river capture on hydrography and water resources: Case study of Ula and Katra catchments, south Lithuania," Holocene, vol. 19, no. 8, pp. 1233-1240, 2009.

[17] L. F. Bloxom and T. J. Burbey, "Determination of the location of the groundwater divide and nature of groundwater flow paths within a region of active stream capture; the New River watershed, Virginia, USA," Environ. Earth Sci., vol. 74, no. 3, pp. 2687-2699, 2015.

[18] D. H. Shugar et al., "River piracy and drainage basin reorganization led by climate-driven glacier retreat," Nat. Geosci., vol. 10, no. 5, pp. 370-375, 2017.

[19] H. W. Beeson, S. W. McCoy, and A. Keen-Zebert, "Geometric disequilibrium of river basins produces long-lived transient landscapes," Earth Planet. Sci. Lett., vol. 475, pp. 34-43, 2017.

[20] L. Goren, S. D. Willett, F. Herman, and J. Braun, "Coupled numerical-analytical approach to landscape evolution modeling," Earth Surf. Process. Landforms, vol. 39, no. 4, pp. 522-545, 2014. 
613 [21] S. D. Willett, S. W. McCoy, T. J. Perron, L. Goren, and C. Y. Chen, "Dynamic

614

615

616

617

618

619

620

621

622

623

624

625

626

627

628

629

630

631

632

633

634

635

636

637 reorganization of River Basins,” Science (80-. )., vol. 343, no. 6175, 2014.

[22] L. Royden and J. Taylor Perron, "Solutions of the stream power equation and application to the evolution of river longitudinal profiles," J. Geophys. Res. Earth Surf., vol. 118, no. 2, pp. 497-518, 2013.

[23] M. P. Dahlquist, A. J. West, and G. Li, "Landslide-driven drainage divide migration," Geology, vol. 46, no. 5, pp. 403-406, 2018.

[24] Y. C. Chen, K. Y. Cheng, W. S. Huang, Q. C. Sung, and H. Tsai, "The relationship between basin hypsometric integral scale dependence and rock uplift rate in a range front area: A case study from the coastal range, Taiwan," J. Geol., vol. 127, no. 2, pp. 223-239, 2019.

[25] R. El Hamdouni, C. Irigaray, T. Fernández, J. Chacón, and E. A. Keller, “Assessment of relative active tectonics, southwest border of the Sierra Nevada (southern Spain)," Geomorphology, vol. 96, no. 1-2, pp. 150-173, 2008.

[26] O. M. A. Radaideh and J. Mosar, "Tectonics controls on fluvial landscapes and drainage development in the westernmost part of Switzerland: Insights from DEM-derived geomorphic indices," Tectonophysics, vol. 768, no. February, p. $228179,2019$.

[27] J. T. Perron and L. Royden, “An integral approach to bedrock river profile analysis," Earth Surf. Process. Landforms, vol. 38, no. 6, pp. 570-576, 2013.

[28] C. B. Dimalanta, L. O. Suerte, G. P. Yumul, R. A. Tamayo, and E. G. L. Ramos, "A Cretaceous supra-subduction oceanic basin source for Central Philippine ophiolitic basement complexes: Geological and geophysical constraints," Geosci. J., vol. 10, no. 3, pp. 305-320, 2006.

[29] J. N. Salomon, "A Mysterious Karst: the 'Chocolate Hills' of Bohol 
(Philippines)," Acta Carsologica, vol. 40, no. 3, pp. 429-444, 2011.

[30] T. Kobayashi, "Remarkable ground uplift and reverse fault ruptures for the 2013 Bohol earthquake ( Mw 7.1 ), Philippines, revealed by SAR pixel offset analysis," Geosci. Lett., vol. 1, no. 7, pp. 1-10, 2014.

[31] W. Schwanghart and D. Scherler, "Short Communication: TopoToolbox 2 MATLAB-based software for topographic analysis and modeling in Earth surface sciences," Earth Surf. Dyn., vol. 2, no. 1, pp. 1-7, 2014.

[32] S. Nath, R. S. Chatterjee, S. P. Mohanty, and S. Gaurav, "Comparative Evaluation of Active Tectonics in Parts of the Frontal Region of NW Himalaya, India by Geomorphic Analysis and Geophysical Investigation,” J. Geol. Soc. India, vol. 94, no. 2, pp. 197-205, 2019.

[33] F. Pavano, G. Romagnoli, G. Tortorici, and S. Catalano, "Morphometric evidences of recent tectonic deformation along the southeastern margin of the Hyblean Plateau (SE-Sicily, Italy),” Geomorphology, vol. 342, pp. 1-19, 2019.

[34] W. Schwanghart, “Chi inferiority," 2018. [Online]. Available: https://topotoolbox.wordpress.com/2018/12/31/x-inferiority/. [Accessed: 20Sep-2003].

[35] S. G. Catane, J. Foronda, and C. J. Tomarong, “Assessment of Hazards Resulting from the July 11, 2005 Landslide , Barangay Mayana, Jagna, Bohol. A report to the Local Government Unit of Jagna, Bohol,” National Institute of Geological Sciences University of the Philippines, Diliman, Quezon City, 2005.

Table 1 Divide stability analysis parameter

\begin{tabular}{ll}
\hline Parameters & Value \\
\hline minimum accumulation area & $45000 \mathrm{~m}^{2}(50$ pixels $)$ \\
\hline
\end{tabular}


theta

0.45

minimum elevation

$1 \mathrm{~m}$

660 
Figures
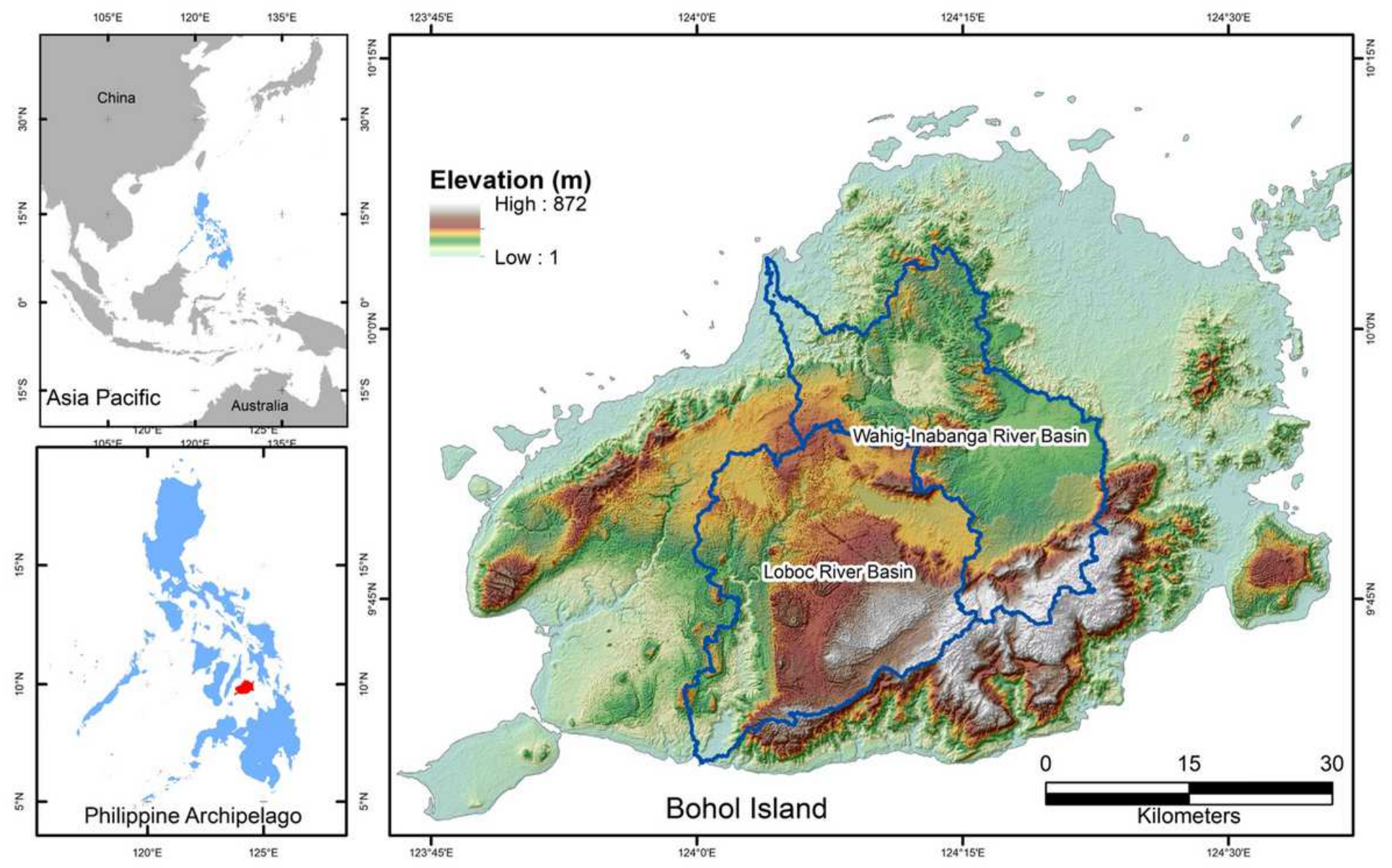

Figure 1

Geographic location of the study site. Note: The designations employed and the presentation of the material on this map do not imply the expression of any opinion whatsoever on the part of Research Square concerning the legal status of any country, territory, city or area or of its authorities, or concerning the delimitation of its frontiers or boundaries. This map has been provided by the authors. 


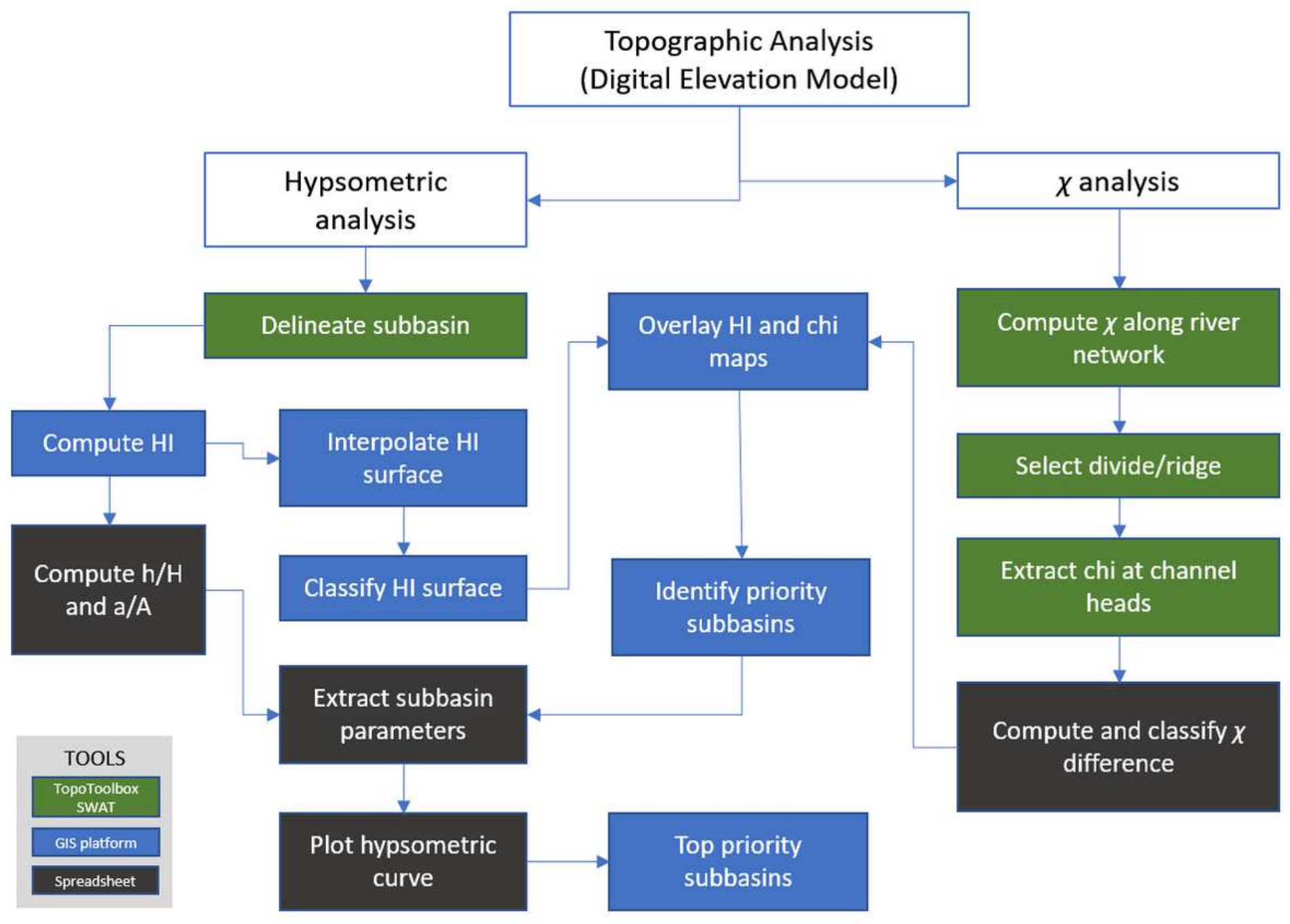

Figure 2

Flow of analysis and the methods.
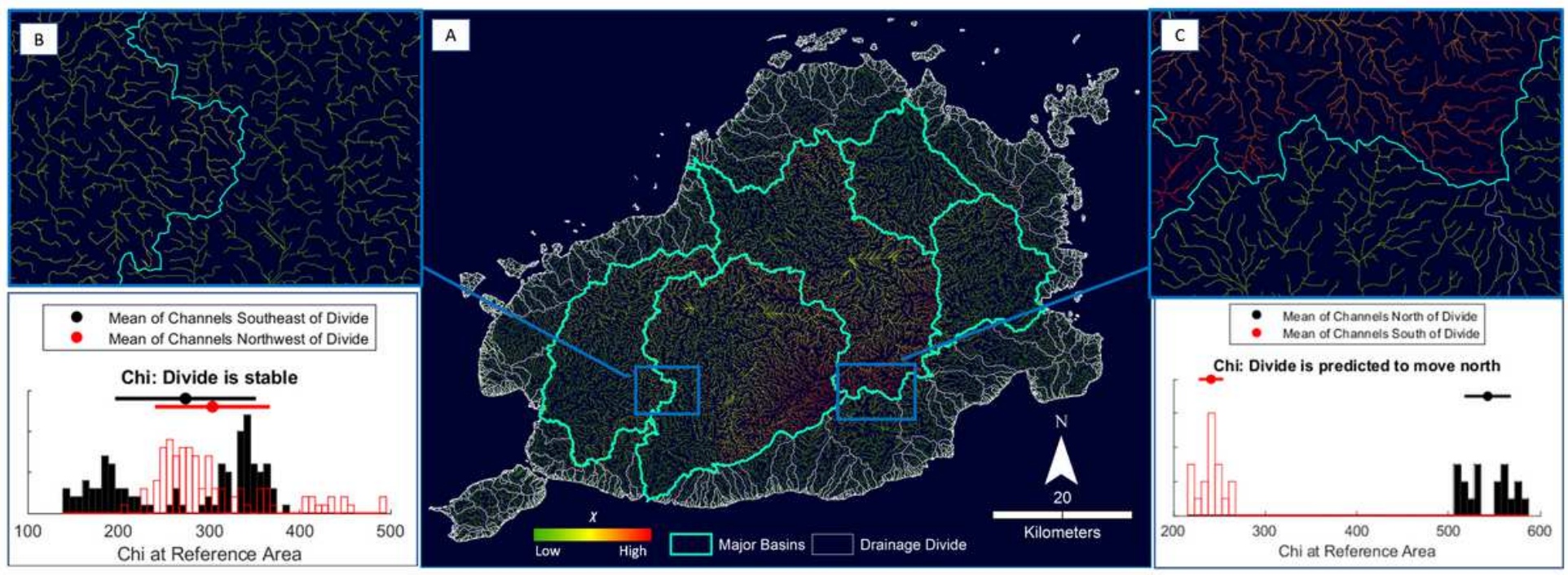

\section{Figure 3}


$\chi$ - map and the major basins in the study area. A) Highlights the major basins in the island. B) $\chi$ - map of a stable divide and its histogram. C) $\chi$ - map of an unstable divide and its histogram. Note: The designations employed and the presentation of the material on this map do not imply the expression of any opinion whatsoever on the part of Research Square concerning the legal status of any country, territory, city or area or of its authorities, or concerning the delimitation of its frontiers or boundaries. This map has been provided by the authors.

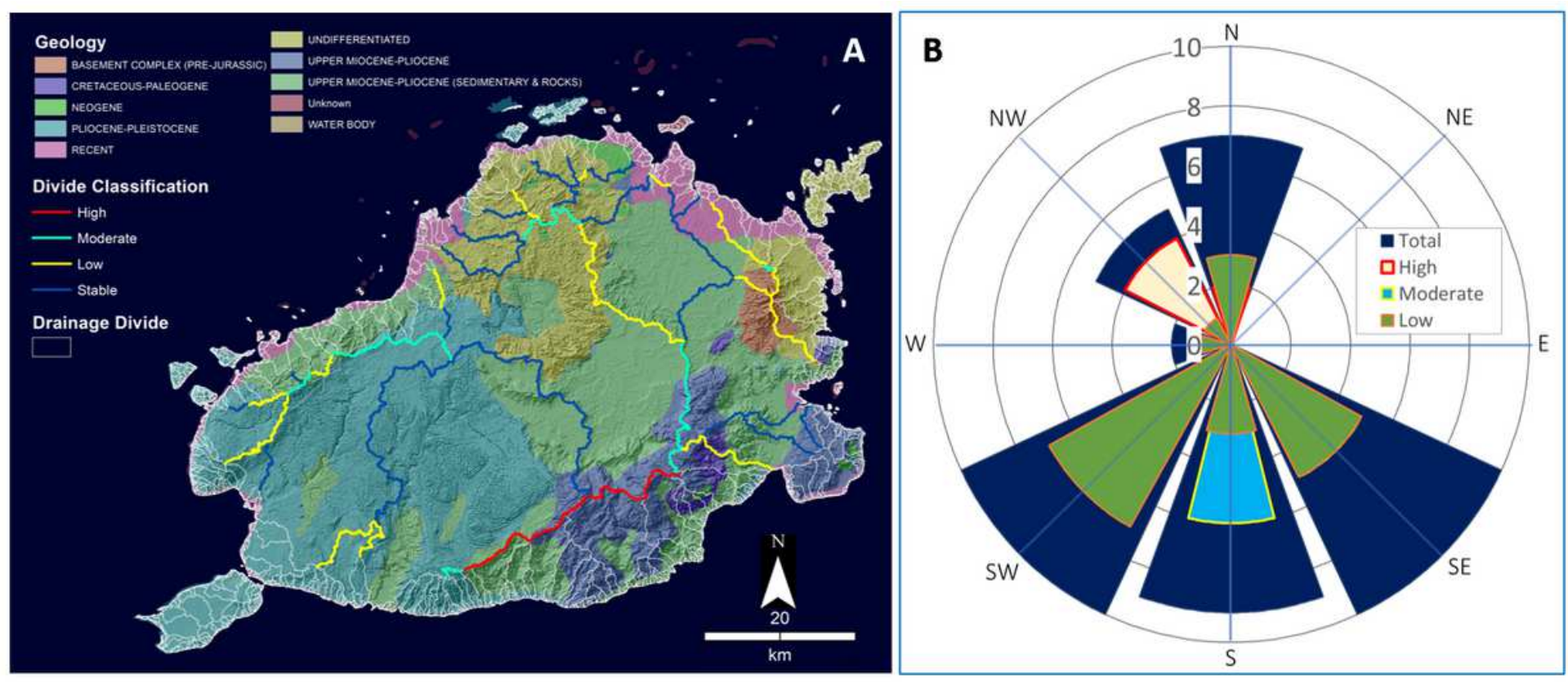

\section{Figure 4}

Divide sections' $\chi m$ m and direction of migration. A) Divide sections colored according to $x m$ classification and laid over the geology of the area. B) A rose diagram showing the direction of potential migration of unstable divides. Note: The designations employed and the presentation of the material on this map do not imply the expression of any opinion whatsoever on the part of Research Square concerning the legal status of any country, territory, city or area or of its authorities, or concerning the delimitation of its frontiers or boundaries. This map has been provided by the authors.
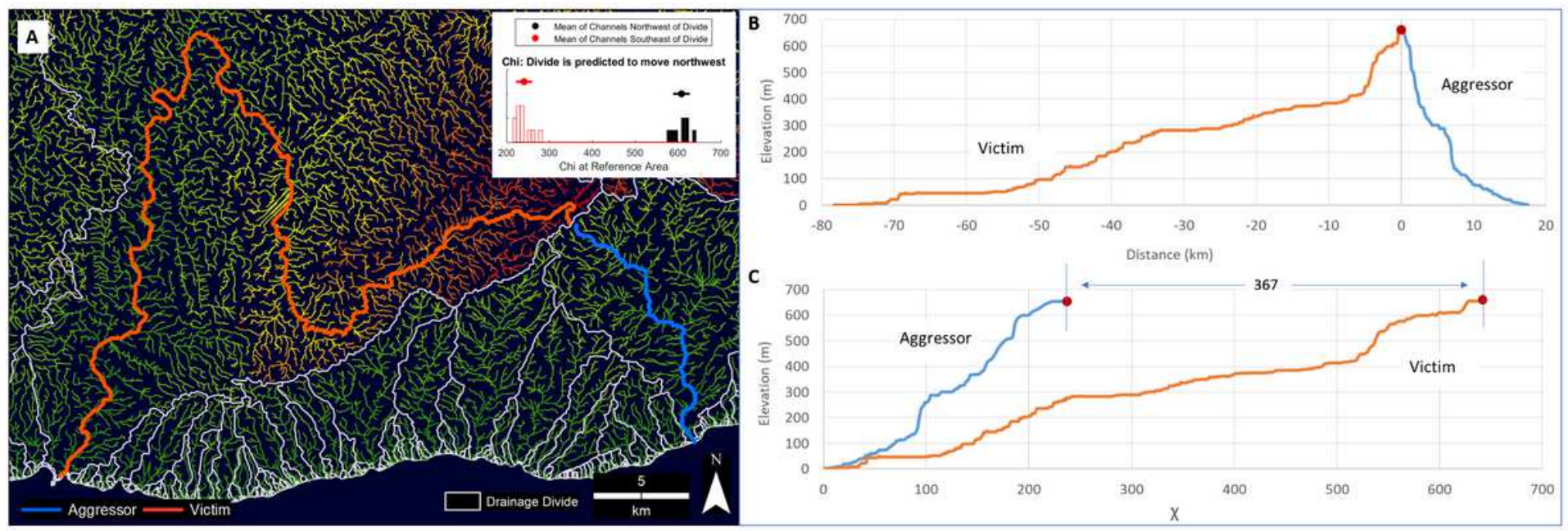


\section{Figure 5}

$\chi$-map of disequilibrium basins and the profiles of the two opposing river networks that meet at the divide. A) Map view of the pathways of two opposing rivers (Inset: histogram showing wide difference of the chi values). B) Longitudinal profile of the opposing streams. C) $\chi$-transformed profile of the two opposing rivers. Note: The designations employed and the presentation of the material on this map do not imply the expression of any opinion whatsoever on the part of Research Square concerning the legal status of any country, territory, city or area or of its authorities, or concerning the delimitation of its frontiers or boundaries. This map has been provided by the authors.

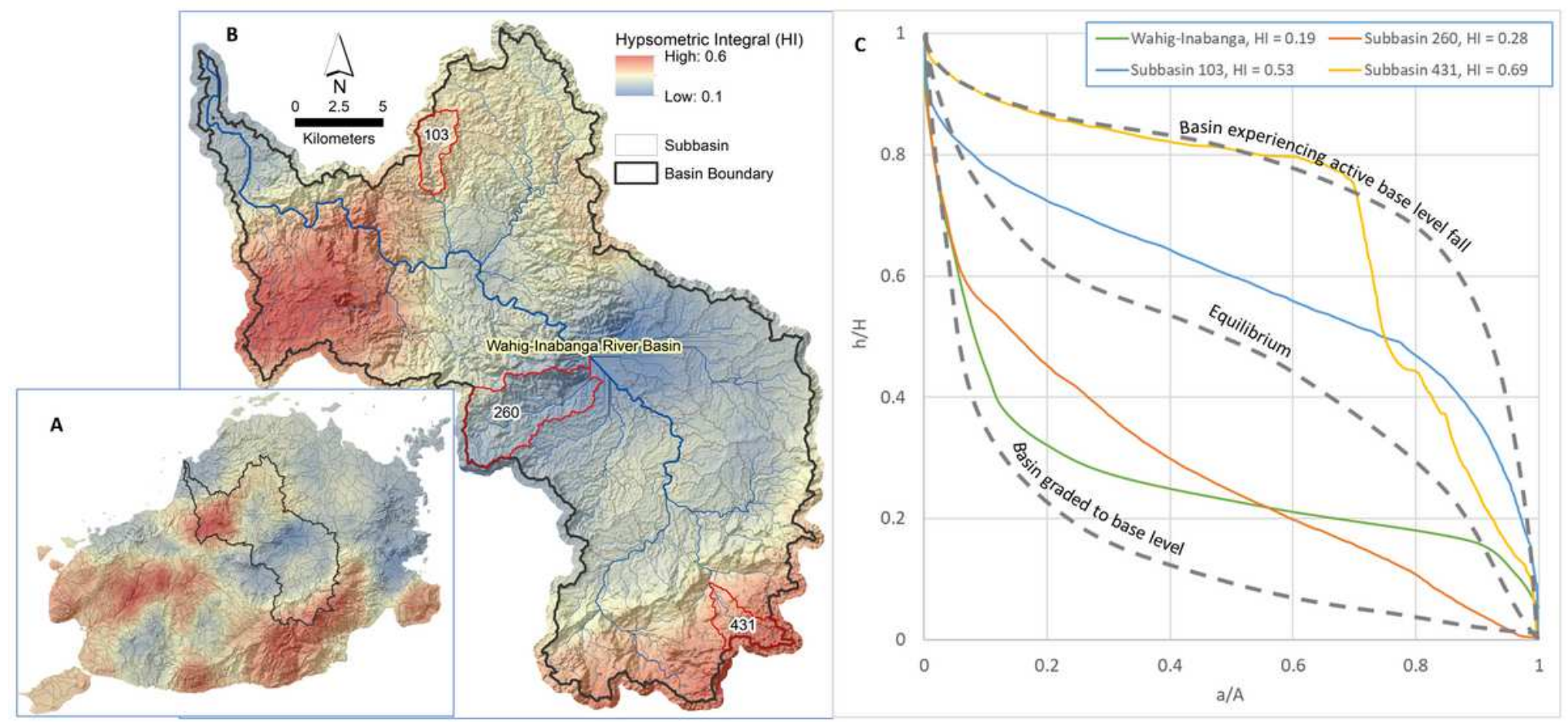

\section{Figure 6}

Spatial variation of the hypsometric integral in A) island and in the B) major basin. C) hypsometric curves of the basin and selected subbasins. Reference hypsometric curves adopted from Pavano et al. (2019). Note: The designations employed and the presentation of the material on this map do not imply the expression of any opinion whatsoever on the part of Research Square concerning the legal status of any country, territory, city or area or of its authorities, or concerning the delimitation of its frontiers or boundaries. This map has been provided by the authors. 


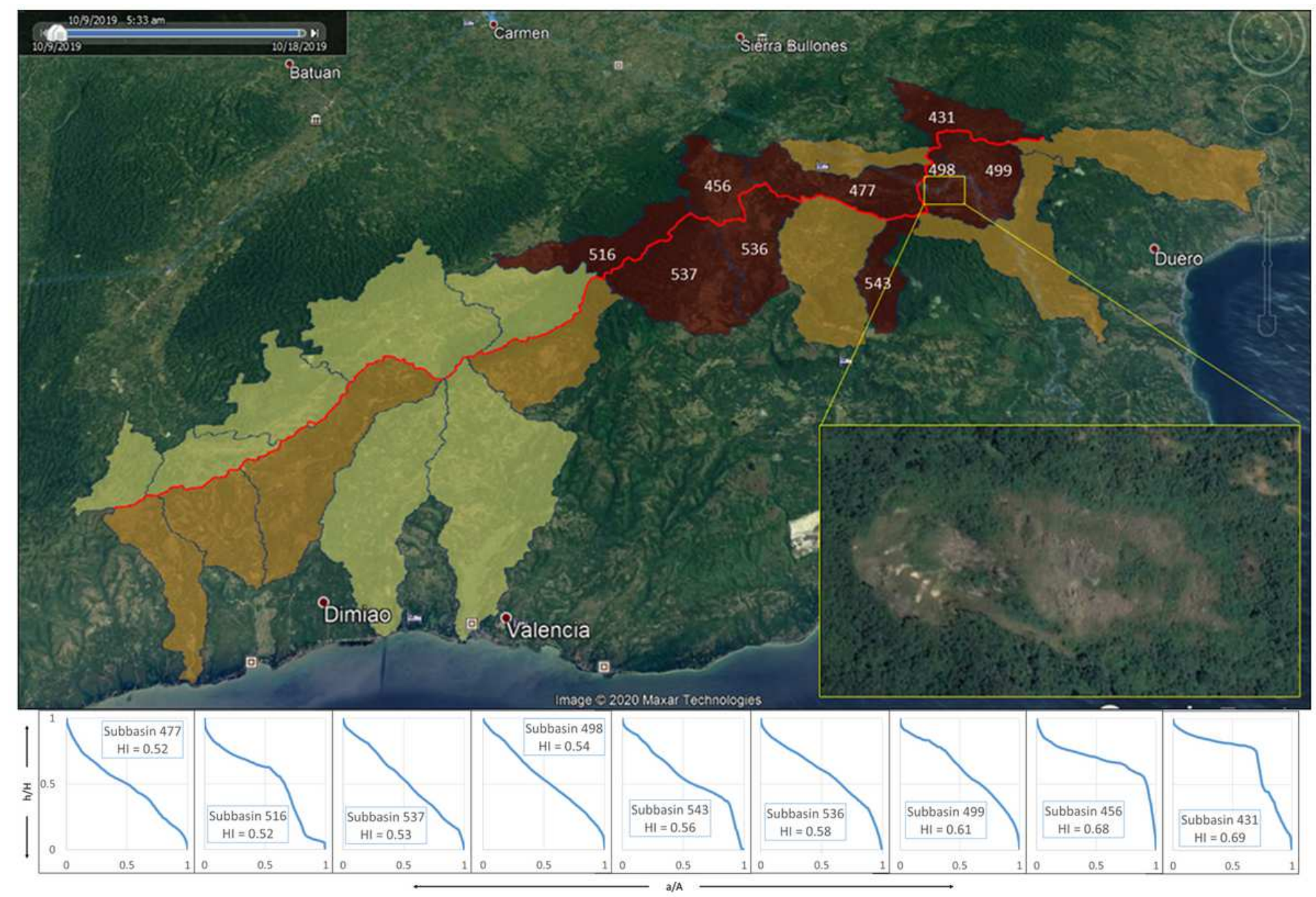

\section{Figure 7}

Map of the subbasins that share with high $\chi$ md divide sections. The color indicates $\mathrm{HI}$ values (light to dark means low to high $\mathrm{HI}$ ). The dark-colored subbasins have $\mathrm{HI} \geq 0.5$. In one of these subbasins, the 2005 Mayana landslide had occurred. Inset is the latest satellite image of the landslide area extracted from Google Earth. Below are the hypsometric curves of the nine subbasins arranged from low to high $\mathrm{HI}$ values. Note: The designations employed and the presentation of the material on this map do not imply the expression of any opinion whatsoever on the part of Research Square concerning the legal status of any country, territory, city or area or of its authorities, or concerning the delimitation of its frontiers or boundaries. This map has been provided by the authors.

\section{Supplementary Files}

This is a list of supplementary files associated with this preprint. Click to download.

- summarychidifferenceanalysis.xlsx

- summaryhypsometricanalysis.xlsx 